\title{
Intra/extracardiac fenestrated modification leads to lower incidence of arrhythmias after the Fontan operation
}

\author{
Pranava Sinha, MD, ${ }^{\mathrm{a}}$ David Zurakowski, PhD, ${ }^{\mathrm{b}}$ Dingchao He, MD, ${ }^{\mathrm{a}}$ Can Yerebakan, MD, ${ }^{\mathrm{a}}$ \\ Vicki Freedenberg, RN, ${ }^{\mathrm{c}}$ Jeffrey P. Moak, MD, ${ }^{\mathrm{c}}$ and Richard A. Jonas, MD ${ }^{\mathrm{a}}$
}

Objective: The study objective was to compare the incidence of short- and intermediate-term arrhythmias among 3 different surgical modifications of the Fontan procedure.

\begin{abstract}
Methods: We performed a retrospective review of all patients who underwent the Fontan operation at a single institution between January 2004 and May 2010 for preoperative, perioperative, and follow-up variables. Three surgical modifications were studied: intra/extracardiac conduit with limited atriotomy, standard extracardiac conduit, and lateral tunnel. Rhythm was classified as normal or abnormal. A rhythm dysfunction grading was devised and used to identify worsening of rhythm for patients with abnormal rhythm preoperatively. Multivariable logistic regression was used to determine predictors of abnormal rhythm. To eliminate confounding effects of transient immediate postoperative arrhythmias, data were analyzed for abnormal rhythm within the first 2 weeks and for more than 2 weeks after surgery.

Results: Of the 134 patients ( $\mathrm{n}=50$ with intra/extracardiac conduit with limited atriotomy, $\mathrm{n}=19$ with standard extracardiac conduit, $\mathrm{n}=65$ with lateral tunnel) (median follow-up, 36 months; interquartile range, 22-50 months; 2 operative deaths and 6 late deaths), rhythm data for more than 2 weeks postoperatively were available in 88 (40 with lateral tunnel, 14 with standard extracardiac conduit, 34 with intra/extracardiac conduit with limited atriotomy). These patients constituted the study groups. Patients in the lateral tunnel group were relatively younger at the time of the Fontan operation $(P<.001)$ and had a longer follow-up $(P<.001)$. Multivariable logistic regression confirmed that greater than moderate atrioventricular valve regurgitation was the only independent predictor of abnormal rhythm during the first 2 postoperative weeks. Older age at Fontan (odds ratio, 1.20; $95 \%$ confidence interval, $1.05-1.38 ; P=.012$ ) and higher preoperative mean pulmonary artery pressure (odds ratio, $1.2 ; 95 \%$ confidence interval, $1.03-1.44 ; P=.026$ ) were predictors of abnormal rhythm more than 2 weeks postoperatively. Intra/extracardiac conduit with limited atriotomy Fontan modification was associated with a significantly lower incidence of abnormal rhythm after 2 weeks postoperatively compared with lateral tunnel modification (odds ratio, $0.28 ; 95 \%$ confidence interval, $0.10-0.84 ; P=.015$ ).
\end{abstract}

Conclusions: Intra/extracardiac conduit with limited atriotomy Fontan modification has a significantly lower risk of abnormal rhythm postoperatively in the short and intermediate term when compared with the lateral tunnel. (J Thorac Cardiovasc Surg 2013;145:678-82)

Since the introduction of the Fontan operation, ${ }^{1}$ it has undergone multiple modifications. The present popular modifications, the extracardiac (EC) conduit $^{2}$ and lateral tunnel (LT) techniques, ${ }^{3}$ have their advantages and limitations. ${ }^{4}$ Described in $1987,{ }^{5}$ the intra/extracardiac (IE) conduit modification combines the advantages of both the

From Cardiovascular Surgery, ${ }^{a}$ Children's National Medical Center, Washington, DC; Anesthesia and Surgery, ${ }^{\mathrm{b}}$ Children's Hospital Boston, Harvard Medical School, Boston, Mass; and Cardiology, ${ }^{\mathrm{c}}$ Children's National Medical Center, Washington, DC.

Disclosures: Authors have nothing to disclose with regard to commercial support. Received for publication Sept 28, 2011; revisions received March 20, 2012; accepted for publication March 28, 2012; available ahead of print May 11, 2012.

Address for reprints: Richard A. Jonas, MD, Children's National Heart Institute, Cohen Funger Professor of Surgery, Children's National Medical Center, 111 Michigan Avenue NW, Washington, DC 20010 (E-mail: rjonas@cnmc.org). $0022-5223 / \$ 36.00$

Copyright (c) 2013 by The American Association for Thoracic Surgery doi:10.1016/j.jtcvs.2012.03.080 above techniques. Originally reserved for patients with anatomy unsuitable for other modifications, the IE conduit modification is now our universally preferred technique because of the ease of fenestration, simplicity and reproducibility, and minimal disruption of atrial conduction pathways. ${ }^{4}$ We present our experience with the IE Fontan operation in the short and intermediate term, especially with regard to arrhythmias.

\section{MATERIALS AND METHODS}

A retrospective review of all patients who underwent the Fontan operation between January 2004 and May 2009 was performed. The study was approved by the institutional review board of the Children's National Medical Center, and waiver of informed consent was obtained.

Patients with inadequate follow-up data were excluded from the study. Patients were divided into 3 groups according to the Fontan modification performed: IE conduit, EC, and LT Fontan.

Rhythm data were obtained by analysis of available electrocardiograms and Holter examinations by a single electrophysiologist (J.M.) blinded to the Fontan modification. 


$$
\begin{aligned}
& \text { Abbreviations and Acronyms } \\
& \begin{aligned}
\mathrm{CI} & =\text { confidence interval } \\
\mathrm{CPB} & =\text { cardiopulmonary bypass } \\
\mathrm{EC} & =\text { extracardiac } \\
\mathrm{HR} & =\text { heart rate } \\
\mathrm{IE} & =\text { intra/extracardiac } \\
\mathrm{LT} & =\text { lateral tunnel } \\
\mathrm{OR} & =\text { odds ratio } \\
\mathrm{SD} & =\text { standard deviation }
\end{aligned}
\end{aligned}
$$

Rhythm was classified as normal or abnormal. The abnormal group constituted sinus node dysfunction or others (ectopic atrial tachycardia, junctional ectopic tachycardia, paced rhythm). A scoring system was devised, and sinus node dysfunction was graded as mild: less than $35 \%$ junctional rhythm, average heart rate (HR) within 2 standard deviations (SDs) for age, no chronotropic incompetence, and no prolonged pauses; moderate: $35 \%$ to $75 \%$ junctional rhythm, average HR within 2 SDs for age, chronotropic incompetence (maximum HR during exercise $75 \%-90 \%$ predicted maximum), and prolonged pauses greater than 2.0 to less than 2.5 seconds; or severe: greater than $75 \%$ junctional rhythm, average HR less than 2 SDs for age, chronotropic incompetence (maximum HR during exercise $<75 \%$ predicted maximum), and prolonged pauses greater than 2.5 seconds.

\section{Statistical Analysis}

Preoperative, intraoperative, and postoperative data were compared between the groups using the chi-square test for categoric variables and analysis of variance for continuous variables. Age was compared using the nonparametric Mann-Whitney $U$ test. Survival was analyzed with the Kaplan-Meier method with the log-rank test used for comparing Fontan modification groups and Greenwood's formula for constructing 95\% confidence intervals (CIs) around the curves. ${ }^{6}$

Multivariable logistic regression was used to determine predictors of nonsinus rhythm using the likelihood ratio test and backward selection, including 7 covariates: type of Fontan modification, age at operation, heterotaxy, mean preoperative pulmonary artery pressure, moderate to severe atrioventricular valve regurgitation, cardiopulmonary bypass (CPB) time, and crossclamp time. ${ }^{7}$ We limited the number of covariates in the multivariable data analysis with the rationale of obtaining a more numerically stable model and set of prognostic variables of abnormal sinus rhythm. ${ }^{8}$ Odds ratios (ORs) and $95 \%$ CIs were calculated for significant multivariable predictors. To eliminate confounding effects of transient immediate postoperative arrhythmias, data were analyzed for abnormal rhythm during the first 2 postoperative weeks and more than 2 weeks after surgery. Holter data were compared for intergroup differences in abnormal rhythm by Kruskal-Wallis test and logistic regression analysis.

\section{RESULTS}

A total of 134 patients underwent the Fontan operation during the study period $(n=50$ IE, $n=19 E C, n=65$ LT). There were 2 operative deaths in the entire series, both in the LT group (Fontan baffle thrombosis in 1 patient and sepsis and multiorgan failure in 1 patient). There were 5 late deaths (4 in the LT group, 1 in the EC group) (plastic bronchitis in 2 patients, protein-losing enteropathy in 2 patients, and progressive systemic ventricular failure in 1 patient). Kaplan-Meier estimated survival for the entire cohort was $97 \%, 96 \%$, and $94 \%$ at 6 months, 1 year, and 5 years, respectively (Figure 1, A). No difference in survival was noted among the 3 Fontan modifications (Figure 1, B).

After excluding patients with inadequate follow-up data, 88 patients (34 in the IE group, 14 in the EC group, and 40 in the LT group) comprised the rhythm study group. Median follow-up was 36 months (range, 22-50 months) (24 [8-34] months in the LT group, 2 [1-33] months in the EC group, 8 [1-12] months in the IE group, $P<.001)$.

Age in the LT group was significantly less compared with the other 2 groups (Table 1). A greater number of patients with heterotaxy syndrome were observed and CPB time was longer in the EC group. All patients with the IE and LT modifications had a fenestration, whereas only $64 \%$ in the EC group were fenestrated $(P<.001)$. The intensive care unit stay was shorter in the IE group, although it did not achieve significance. No differences were noted among the groups with respect to other variables (Table 1).

Multivariable logistic regression confirmed that moderate or greater atrioventricular regurgitation was the only predictor of abnormal rhythm within the first 2 weeks postoperatively $(P=.002)$. Older age at Fontan (OR, 12.0; 95\% CI, $1.05-1.38 ; P=.012)$ and higher preoperative mean pulmonary artery pressure (OR, $1.21 ; 95 \%$ CI, 1.03-1.44; $P=.026$ ) were predictors of abnormal rhythm after 2 weeks postoperatively. IE Fontan modification was associated with a significantly lower incidence of abnormal rhythm after 2 weeks postoperatively compared with other modifications $(P=.015$; OR, $0.28 ; 95 \% \mathrm{CI}, 0.10-0.84)$ (Figure 2, $A$; Table 2). Worsening of rhythm according to the proposed grading system was significantly lower in the IE group compared with the LT group (21 [52\%] LT, 2 [14\%] EC, $8[23 \%]$ IE, $P=.01)$. This difference was not significant compared with the EC group (Figure 2, B).

Holter data were available in only $37 \%$ of patients (49/134) overall and $43 \%$ of patients (38/88) in the rhythm study group (10 [29\%] in the IE group, $21[52 \%]$ in the LT group, and $7[50 \%]$ in the EC group, $P=.31$ ) at a median of 198 days (interquartile range, 50-495) postoperatively (98 days [34-380] in the IE group, 381 days [110-934] in the LT group, and 27 days [6-57] in the EC group) $(P=.005$, Kruskal-Wallis test). Abnormalities were detected in $68 \%$ of Holter examinations, as opposed to $42 \%$ of all studies. Abnormal rhythm by Holter was not significantly different among the groups $(81 \%$ in the LT group, $43 \%$ in the EC group, and $60 \%$ in the IE group, $P=.14$ ). Logistic regression analysis comparing the incidence of $a b-$ normal rhythm, detected on Holter, controlling for varying follow-up time showed no significant differences among the 3 groups $(P=.11)$. In addition, no significant differences were found in the percentage of abnormality with increasing follow-up $(P=.19)$. 
Kaplan-Meier Survival for Entire Study Population ( $\mathrm{N}=134)$

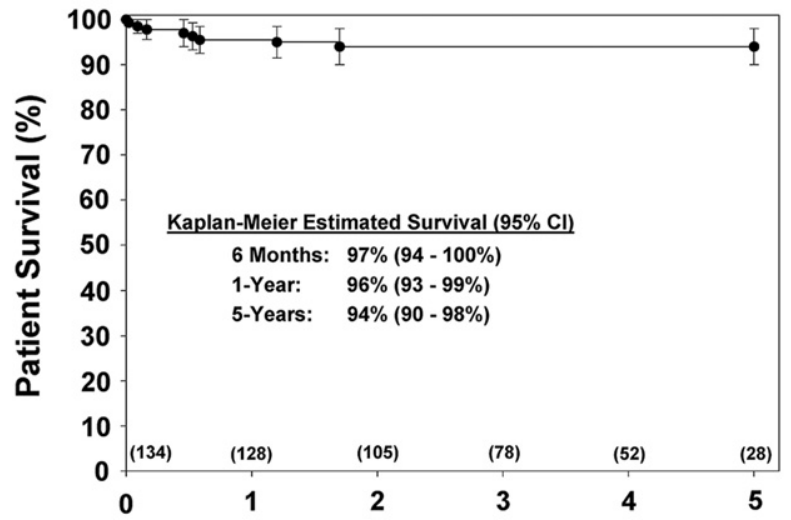

A

Time Since Surgery (years)
Kaplan-Meier Survival Stratified by Type of Fontan Modification

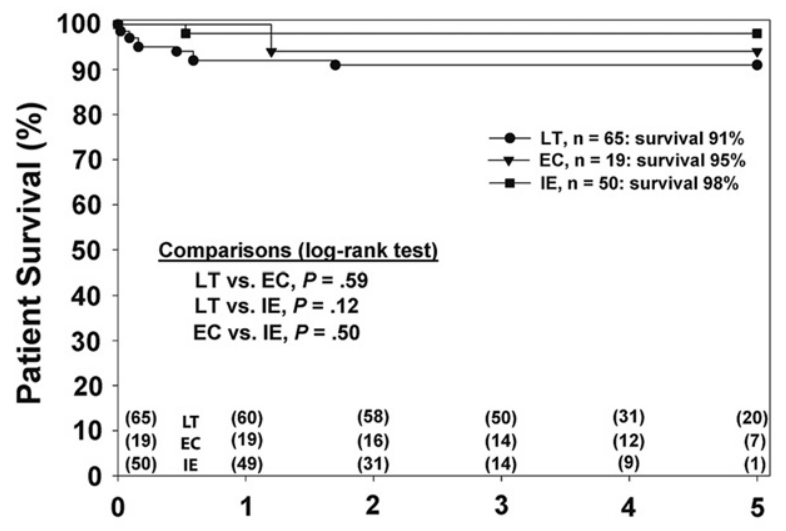

B

FIGURE 1. Kaplan-Meier survival curve for the entire study group (A) and stratified by Fontan modification (B). $C I$, Confidence interval; $L T$, lateral tunnel; $E C$, extracardiac; $I E$, intra/extracardiac.

\section{DISCUSSION}

Arrhythmias continue to be one of the leading causes of morbidity early and late after the Fontan procedure. ${ }^{9-13}$ Atrial arrhythmias after the Fontan operation are consequent to the extensive atrial suture lines and high intra-atrial pressure along with the injury to the sinoatrial node or disruption of its blood supply. ${ }^{12,14-16}$ Avoiding atrial incisions and extensive atrial suture lines, dissection, and incisions along the superior cavoatrial junction ${ }^{14,17,18}$ with the EC modification has failed to conclusively and consistently decrease the incidence of atrial arrhythmias in this group of patients. ${ }^{10,12,13,18-23}$ Preservation of the crista terminalis and eustachian ridge ${ }^{24}$ decreases atrial arrhythmias after the Fontan procedure, ${ }^{25}$ both of which are at

TABLE 1. Preoperative, intraoperative, and postoperative characteristics

\begin{tabular}{|c|c|c|c|c|}
\hline & LT $(n=40)$ & $\mathrm{EC}(\mathrm{n}=14)$ & IE $(\mathbf{n}=34)$ & $P$ value \\
\hline Age (y), median (range) & $1.8(1.3-10.4)$ & $2.7(2.1-18.0) \dagger$ & $2.1(1.5-16.4) \dagger$ & $<.001 *$ \\
\hline \multicolumn{5}{|l|}{ Gender } \\
\hline Male, no. $(\%)$ & $20(50 \%)$ & $8(57 \%)$ & $21(62 \%)$ & \multirow[t]{2}{*}{.59} \\
\hline Female, no. $(\%)$ & $20(50 \%)$ & $7(43 \%)$ & $13(38 \%)$ & \\
\hline $\mathrm{BSA}\left(\mathrm{m}^{2}\right)$, mean $\pm \mathrm{SD}$ & $0.56 \pm 0.20$ & $0.68 \pm 0.33$ & $0.70 \pm 0.36$ & .09 \\
\hline \multicolumn{5}{|l|}{ Diagnosis } \\
\hline HLHS, no. $(\%)$ & $13(33 \%)$ & $2(14 \%)$ & $6(18 \%)$ & .22 \\
\hline Heterotaxy, no. $(\%)$ & $1(3 \%)$ & $6(43 \%) \dagger$ & $9(27 \%) \dagger$ & $<.001^{*}$ \\
\hline \multicolumn{5}{|l|}{ Hemodynamic } \\
\hline $\mathrm{EDP}, \mathrm{mm} \mathrm{Hg}$, mean $\pm \mathrm{SD}$ & $11.1 \pm 2.7$ & $9.1 \pm 2.1$ & $11.2 \pm 3.4$ & .07 \\
\hline Mean PAP, $\mathrm{mm} \mathrm{Hg}$, mean $\pm \mathrm{SD}$ & $14.4 \pm 2.9$ & $13.1 \pm 2.8$ & $13.8 \pm 3.3$ & .43 \\
\hline $\mathrm{TPG}, \mathrm{mm} \mathrm{Hg}$, mean $\pm \mathrm{SD}$ & $4.5 \pm 2.4$ & $4.7 \pm 3.0$ & $4.1 \pm 1.3$ & .67 \\
\hline AVV regurgitation, median (range) & $2(1-4)$ & $1(1-2)$ & $1(1-4)$ & .14 \\
\hline \multicolumn{5}{|l|}{ Intraoperative } \\
\hline $\mathrm{CPB}$ time, min, mean $\pm \mathrm{SD}$ & $81 \pm 15$ & $99 \pm 19 \dagger$ & $90 \pm 18$ & $.002 *$ \\
\hline Crossclamp time, min, mean $\pm \mathrm{SD}$ & $41 \pm 9$ & $35 \pm 20$ & $39 \pm 14$ & .45 \\
\hline Fenestration, no. $(\%)$ & $40(100 \%)$ & $9(64 \%) \ddagger$ & $34(100 \%)$ & $<.001 *$ \\
\hline \multicolumn{5}{|l|}{ Postoperative } \\
\hline Ventilation time, $\mathrm{d}$, median (range) & $1(0-25)$ & $2(0-12)$ & $1(0-7)$ & .13 \\
\hline ICU stay (d) median (range) & $4(1-73)$ & $6(2-53)$ & $3(2-32)$ & .08 \\
\hline Length of stay (d) median (range) & $12(6-73)$ & $16(5-63)$ & $10(5-38)$ & .10 \\
\hline Chest tube drainage, $\mathrm{d}$, median (range) & $8(3-37)$ & $12(4-52)$ & $8(3-37)$ & .27 \\
\hline Follow-up (m) median (range) & $24(8-34)$ & $2(1-33)$ & $8(1-12)$ & $<.001^{*}$ \\
\hline
\end{tabular}

$L T$, Lateral tunnel; $E C$, extracardiac; $I E$, intra/extracardiac; $S D$, standard deviation; $B S A$, body surface area; $H L H S$, hypoplastic left heart syndrome; $E D P$, end-diastolic pressure; $P A P$, pulmonary artery pressure; $T P G$, transpulmonary gradient; $A V V$, atrioventricular valve; $C P B$, cardiopulmonary bypass; $I C U$, intensive care unit. *Statistically significant overall group differences. $\nmid$ Significantly different than LT group. $\ddagger$ Significantly different than LT and IE groups. 

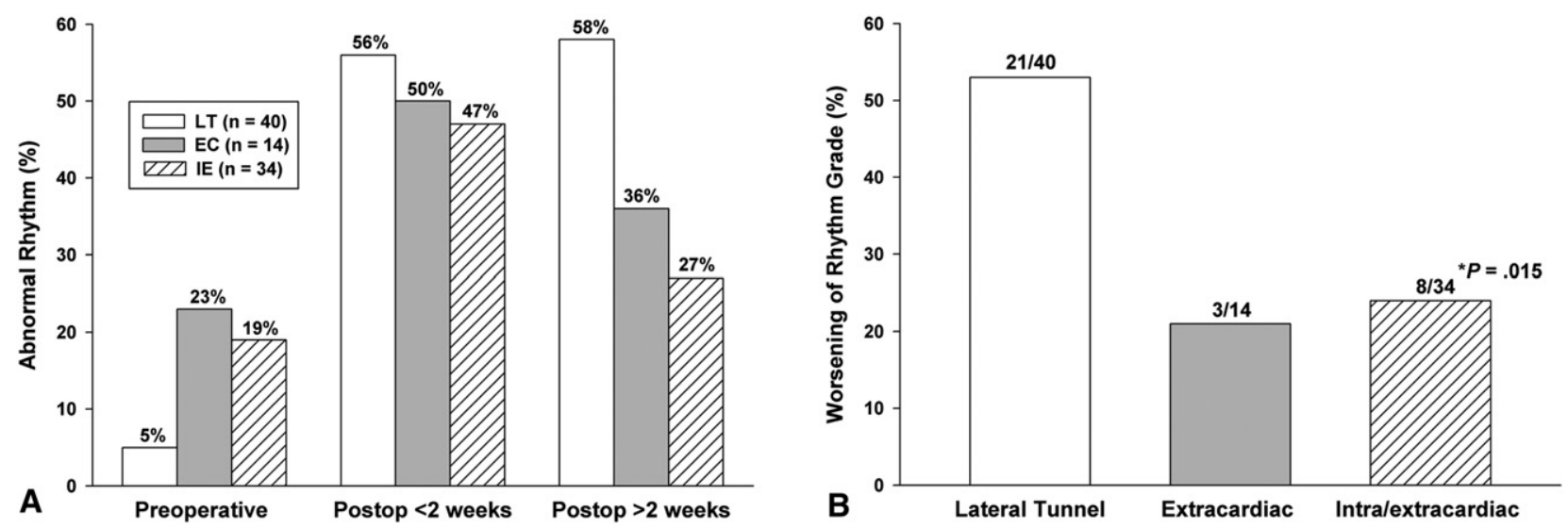

FIGURE 2. A, Incidence of abnormal rhythm with each Fontan modification preoperatively, at less than 2 weeks postoperatively, and at more than 2 weeks postoperatively. B, Worsening of rhythm comparing rhythm preoperatively with more than 2 weeks postoperatively. Significant difference $(P=.015)$ between the IE and LT groups, favoring the IE modification. $L T$, Lateral tunnel; $E C$, extracardiac; $I E$, intra/extracardiac.

risk with the EC Fontan especially if performed off pump or without cardiac arrest.

Routine incorporation of fenestration leads to improvement of immediate postoperative morbidity in terms of reduced pleural effusions, ${ }^{26-28}$ shorter length of hospital stay, ${ }^{27,28}$ and need for additional procedures ${ }^{27}$ as well as reduced late tachyarrhythmias ${ }^{29}$ and Fontan failures ${ }^{26}$ in the long term. It also provides an easy percutaneous access to the common atrium for diagnostic and therapeutic electrophysiologic studies. Despite various ingenious techniques, ${ }^{30-33}$ achievement of a reliable fenestration in the EC modification is difficult. ${ }^{4,30}$

This study clearly demonstrates the superiority of the IE modification over the LT technique by demonstrating a significantly lower incidence of abnormal rhythm after 2 weeks postoperatively. The differences tend to favor the IE modification over the EC modification; however, our results did not achieve statistical significance because of the small number of patients in the EC group.

TABLE 2. Multivariable logistic regression: Predictors of abnormal rhythm after the Fontan operation

\begin{tabular}{|c|c|c|c|c|}
\hline \multirow[b]{2}{*}{ Variable } & \multirow{2}{*}{$\begin{array}{c}\begin{array}{c}\text { Abnormal } \\
\text { rhythm }<2 \text { wk }\end{array} \\
P \text { value }\end{array}$} & \multicolumn{3}{|c|}{$\begin{array}{c}\text { Abnormal } \\
\text { rhythm }>2 \text { wk }\end{array}$} \\
\hline & & $P$ value & OR & $95 \%$ CI \\
\hline Age at Fontan & .437 & $.012^{*}$ & 1.20 & $1.05-1.38$ \\
\hline Heterotaxy & .329 & .132 & & \\
\hline IE vs LT Fontan & .701 & $.015^{*}$ & 0.28 & $0.10-0.84$ \\
\hline Mean PAP & .559 & $.026^{*}$ & 1.21 & $1.03-1.44$ \\
\hline AVV regurgitation grade & $.002^{*}$ & .363 & & \\
\hline CPB time & .502 & .179 & & \\
\hline Crossclamp time & .311 & .544 & & \\
\hline
\end{tabular}

Note: Moderate to severe AVV is associated with a higher risk of abnormal rhythm less than 2 weeks after the Fontan (OR, 6.5, 95\% CI, 1.5-34.0). IE, Intra/extracardiac; $L T$, lateral tunnel; $P A P$, pulmonary artery pressure; $A V V$, atrioventricular valve; $O R$, odds ratio; $C I$, confidence interval; $C P B$, cardiopulmonary bypass. *Statistically significant.
All patients with the IE and LT modifications had a fenestration, whereas only $64 \%$ in the EC group were fenestrated $(P<.001)$. Because the protective effects of fenestration on the incidence of arrhythmias continue in the late postoperative period, ${ }^{26,29}$ the IE group is expected to do better than the EC group with continued follow-up.

The EC group had a greater number of patients with heterotaxy syndrome. These patients often were not suitable for LT modification and historically underwent the EC modification at our center. Longer CPB time in this group reflects the anatomic complexities in this group of patients. However, most of these patients are suitable for the IE technique, and since our universal adoption of this technique, only 2 of 34 patients have undergone an EC modification for anatomic reasons.

The intensive care unit stay was shorter in the IE group and trended to but did not achieve significance (median 4 [range, 1-73] days in the LT group, median 6 [range, 2-53] days in the EC group, median 3 [range, 2-32] days in the IE group, $P=.08$ ).

The IE modification combines the advantages of both the LT and EC modifications and offers ease of reliable fenestration, technical simplicity, and reproducibility. It involves a standard short oblique right atriotomy, as used for most transatrial procedures, without any risk of jeopardizing the sinoatrial node or its vascularity. The crista terminalis and the eustachian ridge are well preserved.

The current study suffers the limitation of being a retrospective, intermediate-term study, with limited patients. With the shift of our preference to adopt the IE modification universally, this group of patients are more recent and compared with the historical LT and EC groups, thus adding the confounding effects of noncontemporary groups and differential length of follow-up to the results. The rhythm data were obtained from serial electrocardiograms 
with approximately more than one third of the patients having Holter data. Abnormalities were detected in $68 \%$ of Holter examinations, as opposed to $42 \%$ of all studies. This could be due to increased sensitivity of the Holter examination in detecting arrhythmias, in addition to a selection bias in this group, because Holter examinations were prompted by clinical suspicion of arrhythmias rather than by protocol. Intergroup differences were nonsignificant, presumably because of the smaller number of patients with Holter data. Because the yield of arrhythmia detection increases with the frequency of observations,${ }^{34}$ it is likely that the incidence of nonsinus rhythm is underestimated in this study.

\section{CONCLUSIONS}

The IE modification is a simple technique that combines the advantages of the LT and EC modifications and leads to a lower incidence of abnormal rhythm in the short and intermediate term. Long-term results of this modification need to be assessed with larger prospective studies.

\section{References}

1. Fontan F, Baudet E. Surgical repair of tricuspid atresia. Thorax. 1971;26:240-8.

2. Backer CL, Deal BJ, Kaushal S, Russell HM, Tsao S, Mavroudis C. Extracardiac versus intra-atrial lateral tunnel Fontan: extracardiac is better. Semin Thorac Cardiovasc Surg Pediatr Card Surg Annu. 2010;14:4-10.

3. Brown JW, Ruzmetov M, Deschner BW, Rodefeld MD, Turrentine MW. Lateral tunnel Fontan in the current era: is it still a good option? Ann Thorac Surg. 2010; 89:556-63.

4. Jonas RA. The intra/extracardiac conduit fenestrated Fontan. Semin Thorac Cardiovasc Surg Pediatr Card Surg Annu. 2011;14:11-8.

5. Vargas FJ, Mayer JE Jr, Jonas RA, Castaneda AR. Anomalous systemic and pulmonary venous connections in conjunction with atriopulmonary anastomosis (FontanKreutzer). Technical considerations. J Thorac Cardiovasc Surg. 1987;93:523-32.

6. Kaplan E, Meier P. Nonparametric estimation of incomplete observations. J Am Stat Assoc. 1958;53:457-81.

7. Katz MH. Chapter 8: Interpreting the results. In: Multivariable analysis: A practical guide for clinicians and public health researchers. 3rd ed. Cambridge, UK: Cambridge University Press; 2011:140-61.

8. Harrell FJ, Lee K, Mark D. Multivariate prognostic models: issues in developing models, evaluating assumptions and adequacy, and measuring and reducing errors. Stat Med. 1996;15:361-87.

9. Anderson PAW, Sleeper LA, Mahony L, Colan SD, Atz AM, Breitbart RE, et al. Contemporary outcomes after the Fontan procedure: a pediatric heart network multicenter study. J Am Coll Cardiol. 2008;52:85-98.

10. Paridon SM, Mitchell PD, Colan SD, Williams RV, Blaufox A, Li JS, et al. A cross-sectional study of exercise performance during the first 2 decades of life after the Fontan operation. J Am Coll Cardiol. 2008;52:99-107.

11. Mavroudis C, Deal BJ, Backer CL, Stewart RD, Franklin WH, Tsao S, et al. 111 Fontan conversions with arrhythmia surgery: surgical lessons and outcomes. Ann Thorac Surg. 2007;84:1457-66.

12. Fishberger SB, Wernovsky G, Gentles TL, Gauvreau K, Burnett J, Mayer JE Jr, et al. Factors that influence the development of atrial flutter after the Fontan operation. J Thorac Cardiovasc Surg. 1997;113:80-6.

13. Blaufox AD, Sleeper LA, Bradley DJ, Breitbart RE, Hordof A, Kanter RJ, et al. Functional status, heart rate, and rhythm abnormalities in 521 Fontan patients 6 to 18 years of age. J Thorac Cardiovasc Surg. 2008;136:100-7.
14. Cohen MI, Wernovsky G, Vetter VL, Wieand TS, Gaynor JW, Jacobs ML, et al. Sinus node function after a systematically staged Fontan procedure. Circulation. 1998;98(19 Suppl):II352-9.

15. Bradley SM. Invited commentary. Ann Thorac Surg. 2004;78:1988.

16. Jonas RA. Comprehensive Surgical Management of Congenital Heart Disease. London: Hodder Arnold; 2004.

17. Cohen MI, Bridges ND, Gaynor JW, Hoffman TM, Wernovsky G, Vetter VL, et al. Modifications to the cavopulmonary anastomosis do not eliminate early sinus node dysfunction. J Thorac Cardiovasc Surg. 2000;120:891-901.

18. Kumar SP, Rubinstein CS, Simsic JM, Taylor AB, Saul JP, Bradley SM. Lateral tunnel versus extracardiac conduit Fontan procedure: a concurrent comparison. Ann Thorac Surg. 2003;76:1389-97.

19. Morales DLS, Dibardino DJ, Braud BE, Fenrich AL, Heinle JS, Vaughn WK, et al. Salvaging the failing Fontan: lateral tunnel versus extracardiac conduit. Ann Thorac Surg. 2005;80:1445-52.

20. Nurnberg JH, Ovroutski S, Alexi-Meskishvili V, Ewert P, Hetzer R, Lange PE. New onset arrhythmias after the extracardiac conduit Fontan operation compared with the intraatrial lateral tunnel procedure: early and midterm results. Ann Thorac Surg. 2004;78:1979-88.

21. Azakie A, McCrindle BW, Van Arsdell G, Benson LN, Coles J, Hamilton R, et al. Extracardiac conduit versus lateral tunnel cavopulmonary connections at a single institution: impact on outcomes. J Thorac Cardiovasc Surg. 2001; 122:1219-28.

22. Dilawar M, Bradley SM, Saul JP, Stroud MR, Balaji S. Sinus node dysfunction after intraatrial lateral tunnel and extracardiac conduit Fontan procedures. Pediatr Cardiol. 2003;24:284-8.

23. Gaynor JW, Bridges ND, Cohen MI, Mahle WT, DeCampli WM, Steven JM, et al. Predictors of outcome after the Fontan operation: is hypoplastic left heart syndrome still a risk factor? J Thorac Cardiovasc Surg. 2002;123:237-45.

24. Olgin JE, Kalman JM, Fitzpatrick AP, Lesh MD. Role of right atrial endocardial structures as barriers to conduction during human type I atrial flutter: activation and entrainment mapping guided by intracardiac echocardiography. Circulation. 1995;92:1839-48.

25. Hashimoto K, Kurosawa H, Tanaka K, Yamagishi M, Koyanagi K, Ishii S, et al. Total cavopulmonary connection without the use of prosthetic material: technical considerations and hemodynamic consequences. J Thorac Cardiovasc Surg. 1995; 110:625-32.

26. Airan B, Sharma R, Choudhary SK, Mohanty SR, Bhan A, Chowdhari UK, et al. Univentricular repair: is routine fenestration justified? Ann Thorac Surg. 2000; 69:1900-6.

27. Lemler MS, Scott WA, Leonard SR, Stromberg D, Ramaciotti C. Fenestration improves clinical outcome of the Fontan procedure: a prospective, randomized study. Circulation. 2002;105:207-12.

28. Bridges ND, Mayer JE Jr, Lock JE, Jonas RA, Hanley FL, Keane JF, et al. Effect of baffle fenestration on outcome of the modified Fontan operation. Circulation. 1992;86:1762-9.

29. Ono M, Boethig D, Goerler H, Lange M, Westhoff-Bleck M, Breymann T. Clinical outcome of patients 20 years after Fontan operation-effect of fenestration on late morbidity. Eur J Cardiothorac Surg. 2006;30:923-9.

30. Ruiz E, Guerrero R, d'Udekem Y, Brizard C. A technique of fenestration for extracardiac Fontan with long-term patency. Eur J Cardiothorac Surg. 2009;36: 200-2.

31. Mir TS, Arndt F, von Samson P, Philipp L, Schnegg C, Mueller G, et al. A novel innominate vein-to-common atrium fenestration at Fontan completion. Ann Thorac Surg. 2010;89:e38-40.

32. Nemoto S, Ikeda T, Brizard CP, Komeda M. [Modified technique creating fenestration in the extracardiac Fontan completion; kissing anastomosis]. Kyobu Geka. 2005;58:875-8.

33. Michel-Behnke I, Luedemann M, Bauer J, Hagel KJ, Akintuerk H, Schranz D. Fenestration in extracardiac conduits in children after modified Fontan operation by implantation of stent grafts. Pediatr Cardiol. 2005;26:93-6.

34. Bass EB, Curtiss EI, Arena VC, Hanusa BH, Cecchetti A, Karpf M, et al. The duration of Holter monitoring in patients with syncope: is 24 hours enough? Arch Intern Med. 1990;150:1073-8. 